\title{
SUDOSCAN, an effective tool for screening chronic kidney disease in patients with type 2 diabetes
}

\author{
FEI MAO $^{1 *}$, SIYING LIU $^{1 *}$, XIAONA QIAO ${ }^{1}$, HANGPING ZHENG $^{1}$, QIAN XIONG $^{1,2}$, JIE WEN $^{1,2}$, \\ SHUO ZHANG ${ }^{1}$, ZHAOYUN ZHANG ${ }^{1}$, HONGYING YE ${ }^{1}$, HONGLI SHI $^{1}$, BIN LU $^{1}$ and YIMING LI ${ }^{1,2}$ \\ ${ }^{1}$ Department of Endocrinology and Metabolism, Huashan Hospital, Fudan University; ${ }^{2}$ Department of \\ Endocrinology and Metabolism, Jing' an Center Hospital of Shanghai, Shanghai 200040, P.R. China
}

Received May 9, 2016; Accepted March 23, 2017

DOI: 10.3892/etm.2017.4689

\begin{abstract}
SUDOSCAN is a non-invasive method of measuring peripheral small fiber and autonomic nerve activity by detection of abnormal sweat gland function through electrochemical skin conductance. It has been reported to be an effective screening tool in early detection of microvascular type 2 diabetes mellitus (T2DM) complications including diabetic neuropathy and nephropathy in recent studies. However, previous studies used estimated glomerular filtration rate (eGFR) as the golden standard, which has a $90 \%$ chance of being within $30 \%$ of the measured GFR at best. No relevant study has been performed in the Chinese population concerning SUDOSCAN in the screening of diabetic nephropathy (DN) in comparison with GFR. In this cross-sectional study, SUDOSCAN was performed in 176 Chinese patients with T2DM between September 2014 and September 2015. It was found that the SUDOSCAN test had a sensitivity of $57.8 \%$ and a specificity of $100 \%$ to detect chronic kidney disease at a cut-off SUDOSCAN-DN score of 59.5. The area
\end{abstract}

Correspondence to: Professor Bin Lu or Professor Yiming Li, Department of Endocrinology and Metabolism, Huashan Hospital, Fudan University, 12 Middle of Wulumuqi Road, Jing'an, Shanghai 200040, P.R. China

E-mail: binlu@fudan.edu.cn

E-mail: yimingli@fudan.edu.cn

*Contributed equally

Abbreviations: T2DM, type 2 diabetes mellitus; BMI, body mass index; DN, diabetic nephropathy; WHR, waist-hip ratio; HbA1c, glycated hemoglobin; LDL-C, low-density lipoprotein cholesterol; HDL-C, high-density lipoprotein cholesterol; BUN, blood urea nitrogen; UACR, urinary albumin-creatinine ratio; GFR, glomerular filtrate rate; ESC, electrochemical skin conductance; MDRD, modification of diet in renal disease; EPI, epidemiology collaboration; CKD, chronic kidney disease; KDOQI, National Kidney Foundation's Kidney Disease Outcomes Quality Initiative

Key words: SUDOSCAN, diabetic nephropathy, type 2 diabetes mellitus, screening, modification of diet in renal disease under receiver operating characteristic curve for DN was 0.85 [95\% confidence interval (CI), 0.76-0.93] compared with 0.84 for eGFR $\mathrm{MDRD}_{\mathrm{MDRD}}$ (Modification of diet in renal disease; 95\% CI, 0.71-0.98) and 0.77 for eGFR EPI $_{\text {(EPI, epidemiology }}$ collaboration; 95\% CI, 0.68-0.87). Patients with DN score $<59.5$ had a significantly lower GFR level $(\mathrm{P}<0.001)$ and significantly older age $(\mathrm{P}<0.001)$, longer duration of $\mathrm{T} 2 \mathrm{DM}$ $(\mathrm{P}<0.001)$ and higher risk of diabetic complications, including diabetic neuropathy $(\mathrm{P}<0.001)$ and peripheral vascular disease $(\mathrm{P}<0.05)$. These results suggested that SUDOSCAN may be useful for detecting patients at risk of impaired renal function as part of a screening program in the Chinese population with T2DM.

\section{Introduction}

Diabetic nephropathy (DN) remains the leading cause of end-stage renal disease, indicated by albuminuria and reduced glomerular filtration rate (GFR) as the predictors for prognosis $(1,2)$. The early identification and monitoring of $\mathrm{DN}$ is one of the major research areas in diabetes, apart from the control of glycemia, hypertension and dyslipidemia. The National Kidney Foundation's Kidney Disease Outcomes Quality Initiative (KDOQI) guidelines (1) recommend using urinary albumin-creatinine ratio (UCAR) and estimated GFR (eGFR) as the screening method for DN during the annual examination for patients with type 2 diabetic mellitus (T2DM), which has facilitated earlier recognition of DN and formed the basis for clinical staging $(1,3)$. Systematic reporting of eGFR using different equations, including modification of diet in renal disease (MDRD) or chronic kidney disease epidemiology collaboration (CKD-EPI) equations, are based on the demographic and laboratory variables, including age and serum creatinine (SCR) level. However, the testing of SCR in an everyday clinical setting may be invasive and costly (3-7).

SUDOSCAN (Impeto Medical SAS, Paris, France) is a non-invasive device for the assessment of sudomotor function through evaluation of sweat gland secretory function as an early reflection of sympathetic nerve impairment (8-10). An electrical current (typically $<4 \mathrm{~V}$ ) is applied to the patients automatically by the device, which allows the electrochemical skin conductance (ESC) of the hands and feet to be evaluated. The device may be used to predict diabetic kidney 
disease with built-in algorithms, by evaluating early deficits in sudomotor function. In a previous cross-sectional study, after adjusting for age, sex, BMI and HbAlc, hands and feet ESC have been demonstrated to be associated with eGFR $\left[<60 \mathrm{ml} / \mathrm{min} / 1.73 \mathrm{~m}^{2}(\mathrm{P}<0.01)\right]$, UACR $[>30 \mathrm{mg} / \mathrm{g}(\mathrm{P}<0.01)]$ and UACR $[>300 \mathrm{mg} / \mathrm{g}(\mathrm{P}<0.01)]$ in populations of European Americans and African Americans with T2DM (11). In a recent study, Luk et al (12) evaluated the clinical utility of SUDOSCAN in detecting CKD and determined the cut-off point for DN score at 53 for detecting patients at risk of CKD by using eGFR as the golden standard. Furthermore, the area under the receiver operating characteristic curve of SUDOSCAN for CKD was 0.75 (95\% confidence interval: 0.72-0.79). However, it has been indicated in other studies that eGFR has $\sim 90 \%$ chance of being within $30 \%$ of the measured GFR at best $(4,5,13)$.

Based on all previously performed studies on SUDOSCAN and its diagnostic value in kidney dysfunction by using eGFR as the golden standard for comparison, the present study decided to use a more direct method to determine kidney function in T2DM patients by using 99mTc-pentetic acid (DTPA) renal dynamic imaging method as the confirmatory golden standard $(14,15)$.

The current study aimed to evaluate the diagnostic value of SUDOSCAN in detecting renal dysfunction of patients with T2DM in comparison with eGFR results calculated by MDRD and EPI by using ${ }^{99} \mathrm{mTc}$-pentetic acid (DTPA) renal dynamic imaging method as the confirmatory golden standard to provide a more comprehensive view into the use of SUDOSCAN in screening CKD in patients with T2DM.

\section{Patients and methods}

Subjects. The present study was conducted in Huashan Hospital, Fudan University (Shanghai, China) from September 2014 to September 2015. The Ethics Committee of Huashan Hospital approved the study. A total of 176 patients (Male: Female 113:63) diagnosed with T2DM, aged 18-80 years, with or without symptoms of nephropathy were continuously enrolled. Written consent was obtained from all patients enrolled in the study. Exclusion criteria were as follows: Undiagnosed hyperglycemia, T1DM diagnosis, treatment with drugs that may have an effect on the sympathetic system such as beta-blockers and antineoplastic drugs, implantation of electrical implantable devices, history of seizures or epilepsy, lumbar sciatic nerve lesion, severe varices of the lower limbs, and other metabolic diseases including thyroid disease or vitamin B12 deficiency.

Physical examination. One trained nurse examined all patients and recorded the results. Basic physical characteristics (height, weight, waist and hip circumference) were measured using standard methods and body mass index (BMI) and waist-hip ratio (WHR) were calculated. Blood pressure was recorded in the supine position following $5 \mathrm{~min}$ of rest. Medical history (diabetes, hypertension, dyslipidemia, cardiovascular disease, cerebrovascular disease and other diseases) was recorded for each patient. Cardiovascular disease was defined as history of coronary heart disease. Cerebrovascular disease was defined as history of stroke.
Laboratory examination. Patients underwent comprehensive metabolic assessments. Blood and urine samples were collected for fasting plasma glucose (FPG), glycated hemoglobin (HbA1c) (1-3), glycated albumin, total cholesterol, low density lipoprotein-cholesterol (LDL-C), high-density lipoprotein-cholesterol (HDL-C), triglyceride (1-3) $(16,17)$, renal function test including serum creatinine, blood urea nitrogen and uric acid and UACR, after $\geq 8 \mathrm{~h}$ of fasting (16). HbAlc and glycated albumin were determined by high-pressure liquid chromatography and liquid enzymatic assay, respectively (14). FPG, total cholesterol, triglyceride, LDL-C, HDL-C and SCR were analyzed using an automatic analyzer (AU640; Olympus Corporation, Tokyo, Japan) (18). Urinary creatinine levels were determined using the alkaline picrate method according to previous studies (12). UACR was calculated as a mean average of albumin $(\mathrm{mg}) /$ creatinine $(\mathrm{g})$ from three repeats. Microalbuminuria was defined as urine ACR $2.5-25.0 \mathrm{mg} / \mathrm{mmol}$ in males and 3.5-25 in females, and macroalbuminuria defined as urine ACR $25.0 \mathrm{mg} / \mathrm{mmol}$ in both, as previously described (12) GFR was measured using the ${ }^{99 \mathrm{~m}}$ Tc-DTPA renal dynamic imaging method (4). eGFR was calculated using two different equations: MDRD recalibrated for Chinese patients and CKD-EPI $(4,19,20)$. MDRD equation was as follows: eGFR $\left(\mathrm{ml} / \mathrm{min} / 1.73 \mathrm{~m}^{2}\right)=186 x(\mathrm{SCRx}$ $0.011)^{-1.154} \mathrm{X}(\text { age })^{-0.203} \mathrm{x}(0.742$ if female/1 if male $) \mathrm{x} 1.233$, where SCR was in $\mu \mathrm{mol} / 1$ and 1.233 was the adjusting coefficient for Chinese patients (12). CKD-EPI equation was as follows: eGFR $\left(\mathrm{ml} / \mathrm{min} / 1.73 \mathrm{~m}^{2}\right)=141 \times \min \left(\mathrm{SCR} / \mathrm{k}, 1^{\mathrm{a}}\right) \times \max (\mathrm{SCR} / \mathrm{k}$, $\left.1^{-1.209}\right) \times\left(0.993^{\text {age }}\right) \times(1.018$ if female/1 if male $)$, where $\mathrm{k}$ is 0.7 for females and 0.9 for males, $\mathrm{a}$ is -0.329 for females and -0.411 for males $(19,20)$.

Peripheral neuropathy and vascular examination. Peripheral sensory polyneuropathy was diagnosed by MNSI B score, which consists of two parts: The appearance of the feet (deformity, dry skin, callus, infection or fissures) and examination of foot ulceration, ankle reflex and vibration perception with a $128 \mathrm{~Hz}$ tuning fork. Evaluation of each parameter was made at both sides with a maximum score of 8 points. The diagnostic criterion of DPN was a MNSI examination score of $\geq 2$, as previously described (21). All assessments were performed by trained nurses and the analysis of results was undertaken by specialists. The ankle-brachial index was detected by ultrasonic Pocket Doppler-Edan-Sonotrax-Basic (Edan-Instruments Inc., Shenzhen, China) Doppler technique, with an $8 \mathrm{MHz}$ probe and mercury sphygmomanometer Riester diplomat-presameter (Rudolf Riester GmbH, Jungingen, Germany) with an adult cuff (arm circumference 24-32 cm). ABI measurements were performed according to previous studies $(22,23)$.

SUDOSCAN test procedure. The SUDOSCAN device is composed of two sets of electrodes for the feet and hands, both of which are connected to a computer for recording and data analysis. The test is non-invasive and no special preparation is required. Patients place the palms of their hands and the soles of their feet on the electrodes for 2-3 min and a low-voltage $(<4 \mathrm{~V})$ electrical current stimulus will be applied by the device automatically. The device is able to measure ESC values expressed in micro-Siemens $(\mu \mathrm{S})$ for the hands and the feet (both right and left sides). The mean of left and right ESC 
values was used for statistical analysis. The machine also has built-in algorithms which integrate ESC with age height, weight and HbAlc level to produce a score that estimates current risk of kidney dysfunction (SUDOSCAN-DN score). The SUDOSCAN procedure was completed by all subjects without any complaints of discomfort and no adverse effects were reported.

Diagnostic criteria. CKD was defined as eGFR $<60 \mathrm{ml} / \mathrm{min} / 1.73 \mathrm{~m}^{2}$. Microalbuminuria was defined as UACR $>30$ and $<300$ and macroalbuminuria was defined as UACR $>300$, according to the criteria of the National Kidney Foundation (24). In the diagnosis of diabetic peripheral sensory polyneuropathy, a cut-off point of $\geq 2$ was used as the diagnosis standard of MNSI B score, based on previous studies $(18,25,26)$. Peripheral vascular disease was defined as non-traumatic lower extremity amputation and/or ankle-brachial ratio $<0.9$ by Doppler ultrasound scan (27).

Statistical analysis. All data are expressed as the mean \pm standard deviation, median (inter-quartile range) or percentages according to different data types. Analysis of variance was used to compare mean differences of clinical factors between two groups and $\chi^{2}$ analyses were used to assess differences between categorical variables. Correlation was determined using Spearman's rho rank tests. Association between ESC value and biological determinants (such as age, gender, BMI, WHR and duration of T2DM) was tested using multiple linear regression analysis. Receiver-operator characteristic (ROC) curves were constructed to evaluate the sensitivity and specificity of SUDOSCAN-DN score in detecting CKD in T2DM patients. The GFR result was used as the gold standard measurement of the degree of neuropathy, based on the cutoff value of $60 \mathrm{ml} / \mathrm{min} / 1.73 \mathrm{~m}^{2}$. The area under the ROC curve was calculated and the optimal cut-off point was the peak of the curve where the sum of sensitivity and specificity was greatest. SPSS 16.0 software (SPSS, Inc., Chicago, IL, USA) was used for all statistical analyses. $\mathrm{P}<0.05$ was considered to indicate a statistically significant difference.

\section{Results}

Enrolled patients. A total of 176 patients with T2DM (113 males and 63 females) were eligible for the present study. Amongst these patients (mean age, 56.0 10.2 years; median duration of T2DM, 7 years, interquartile range 3-12 years), $15.3 \pm 1.0 \%$ of the subjects had CKD, $19.3 \pm 2.5 \%$ had microalbuminuria and $5.0 \pm 0.7 \%$ had macroalbuminuria.

Clinical and biochemical characteristics. Clinical and biochemical characteristics of the 176 subjects are presented in Table I. Patients with CKD had significantly higher age $(\mathrm{P}<0.01)$, longer duration of T2DM $(\mathrm{P}<0.01)$, higher serum creatinine level $(\mathrm{P}<0.01)$, higher $\mathrm{BUN}(\mathrm{P}<0.05)$ and higher UCAR level $(\mathrm{P}<0.05)$ compared with patients without $\mathrm{CKD}$. The mean GFR value was significantly lower in the CKD group compared with the non-CKD group (48.13 \pm 7.91 vs. $\left.85.83 \pm 15.4 \mathrm{ml} / \mathrm{min} / 1.73 \mathrm{~m}^{2} ; \mathrm{P}<0.001\right)$. Mean SUDOSCAN-DN score was significantly lower in the CKD group compared with the non-CKD group $(44.69 \pm 11.9$ vs. $63.16 \pm 16.5 ; \mathrm{P}<0.001)$.

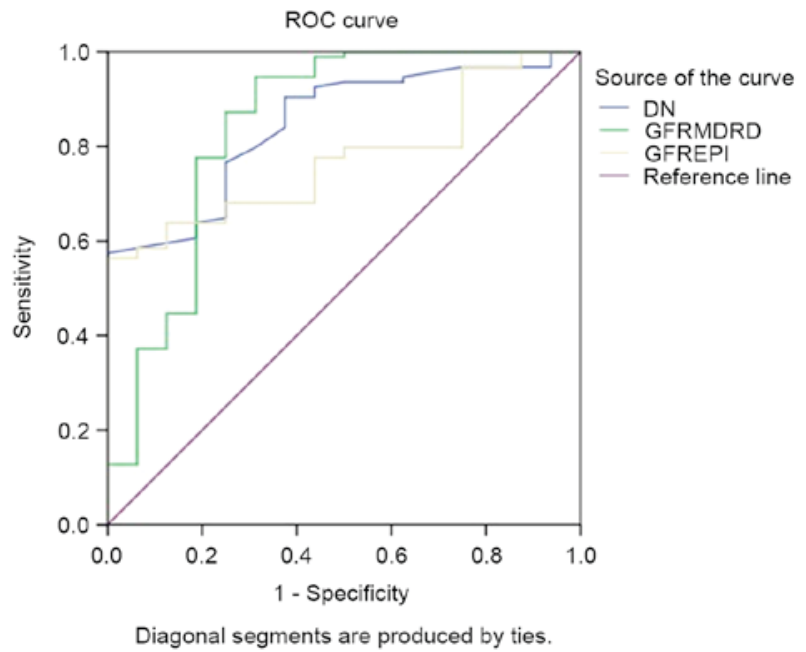

Figure 1. ROC curve of SUDOSCAN-DKD score and estimated glomerular filtration rate calculated using modification of diet in renal disease and epidemiology collaboration equations to detect chronic kidney disease in Chinese patients with type 2 diabetes. ROC, Receiver operating characteristic.

A significantly higher incidence of macroalbuminuria $(27.8 \%$ in $\mathrm{CKD}$ vs. $1 \%$ in non-CKD; $\mathrm{P}<0.001)$, diabetic peripheral neuropathy $(57.9 \%$ in CKD vs. $29.3 \%$ in non-CKD; $\mathrm{P}<0.01)$ and peripheral vascular disease $(10.5 \%$ in CKD vs. $1 \%$ in non-CKD; $\mathrm{P}<0.05$ ) was observed in $\mathrm{CKD}$ patients compared with non-CKD patients. There was no significant difference in the incidence of coronary heart disease or stroke between the two groups. There was also no significant difference in the use of medications between the two groups, including metformin, insulin and anti-hypertension drugs.

Correlation analysis. Spearman correlation analysis (Table II) demonstrated a significant negative correlation between GFR and age $(r=-0.48 ; P<0.01)$, duration of diabetes $(r=-0.22$; $\mathrm{P}<0.05)$, WHR $(\mathrm{r}=-0.25 ; \mathrm{P}<0.01), \mathrm{SCR}(\mathrm{r}=-0.47 ; \mathrm{P}<0.01), \mathrm{BUN}$ level $(\mathrm{r}=-0.306, \mathrm{P}<0.01)$ and uric acid $(\mathrm{r}=-0.307 ; \mathrm{P}<0.01)$. A significant positive correlation was demonstrated between GFR and SUDOSCAN-DN score $(\mathrm{r}=0.52 ; \mathrm{P}<0.01)$, LDL-C $(\mathrm{r}=0.2 ; \mathrm{P}<0.05)$ and blood hemoglobin $(\mathrm{r}=0.22 ; \mathrm{P}<0.05)$.

Multiple linear regression (Table III) indicated that low GFR was significantly associated with low SUDOSCAN-DN score $(\beta$-coefficient $=0.42 ; \mathrm{P}<0.001)$, as well as with older age $(\beta$-coefficient $=-0.368 ; \mathrm{P}<0.001)$, longer disease duration $(\beta$-coefficient $=-0.227 ; \mathrm{P}<0.01)$ and higher WHR $(\beta$-coefficient $=-0.24 ; \mathrm{P}<0.01)$.

ROC curve. The area under the ROC curve of SUDOSCAN-DN score to predict CKD was 0.85 [95\% confidence interval (CI), 0.76-0.93; Fig. 1] compared with 0.84 for $\mathrm{GFR}_{\mathrm{MDRD}}(95 \% \mathrm{CI}$, $0.71-0.98)$ and 0.77 for $\mathrm{GFR}_{\mathrm{EPI}}(95 \% \mathrm{CI}, 0.68-0.87)$. The sensitivity and specificity to detect CKD with SUDOSCAN-DN score was 57.6 and $100 \%$, at a cut-off of 59.5.

Patient comparison. The clinical characteristics of the subjects were further analyzed when patients were divided into two groups by SUDOSCAN-DN score at the cut-off point of 59.5 (Table IV). Patients with DN score $<59.5$ had a significantly higher age, longer duration of T2DM, lower blood hemoglobin 
Table I. Clinical characteristics of patients with T2DM classified by the presence of CKD with normal reference values.

\begin{tabular}{|c|c|c|c|}
\hline Variable & Patients with $\mathrm{CKD}^{\mathrm{a}}(\mathrm{n}=27)$ & Patients without $\mathrm{CKD}^{\mathrm{b}}(\mathrm{n}=149)$ & P-value \\
\hline $\operatorname{Sex}, \mathrm{n}(\mathrm{M} / \mathrm{F})$ & $14 / 13$ & $79 / 70$ & 0.62 \\
\hline Age, years & $67.75 \pm 9.48^{c}$ & $53.01 \pm 11.87$ & $<0.001$ \\
\hline Duration of T2DM, years & $14(8,23)^{\mathrm{c}}$ & $7(3,11)$ & 0.001 \\
\hline Smoking, \% & 15.8 & 31.4 & 0.17 \\
\hline Family history of T2DM, \% & 26.3 & 46.2 & 0.11 \\
\hline \multicolumn{4}{|l|}{ Body mass index, $\mathrm{kg} / \mathrm{m}^{2}$} \\
\hline Male & $24.42 \pm 3.55$ & $24.52 \pm 4.96$ & 0.87 \\
\hline Female & $25.6 \pm 3.1$ & $24.3 \pm 4.5$ & 0.38 \\
\hline \multicolumn{4}{|l|}{ Waist-hip ratio } \\
\hline Male & $1.03 \pm 0.18$ & $0.95 \pm 0.06$ & 0.14 \\
\hline Female & $0.95 \pm 0.1$ & $0.93 \pm 0.08$ & 0.59 \\
\hline Systolic BP, mmHg & $135.25 \pm 15.8$ & $128.5 \pm 15.2$ & 0.091 \\
\hline Diastolic BP, mmHg & $79.63 \pm 11.94$ & $80.57 \pm 9.66$ & 0.79 \\
\hline Glycated hemoglobin, \% (normal range, $<6.5$ ) & $8.8 \pm 2.3$ & $8.7 \pm 2.1$ & 0.93 \\
\hline Glycated albumin, \% (normal range, 5-9) & $20.3 \pm 7.1$ & $21.0 \pm 7.8$ & 0.91 \\
\hline $\begin{array}{l}\text { Fasting blood glucose, } \mathrm{mmol} / \mathrm{l} \\
\text { (normal range: } 3.9-6.1 \text { ) }\end{array}$ & $8.6 \pm 2.8$ & $8.0 \pm 2.6$ & 0.16 \\
\hline $\begin{array}{l}\text { Low-density lipoprotein cholesterol, } \mathrm{mmol} / \mathrm{l} \\
\text { (normal range, <3.36) }\end{array}$ & $2.21(1.81,2.66)$ & $2.47(1.88,2.96)$ & 0.18 \\
\hline $\begin{array}{l}\text { High-density lipoprotein cholesterol, } \mathrm{mmol} / \mathrm{l} \\
\text { (normal range, } 0.9-2.1 \text { ) }\end{array}$ & $1(0.91,1.23)$ & $0.97(0.83,1.2)$ & 0.54 \\
\hline Triglyceride, mmol/l (normal range, 0.6-1.5) & $1.15(0.99,2.2)$ & $1.5(0.96,2.28)$ & 0.62 \\
\hline $\begin{array}{l}\text { Cholesterol, mmol/l } \\
\text { (normal range, 3.1-5.7 mmol/l) }\end{array}$ & $4.22(3.36,4.78)$ & $4.3(3.5,4.92)$ & 0.66 \\
\hline $\begin{array}{l}\text { Serum creatinine, } \mu \mathrm{mol} / 1 \\
\text { (normal range, } 35-71 \text { ) }\end{array}$ & $89.3 \pm 34.6^{\mathrm{c}}$ & $59.6 \pm 14.7$ & $<0.001$ \\
\hline $\begin{array}{l}\text { Blood urea nitrogen, } \mathrm{mmol} / \mathrm{l} \\
\text { (normal range, } 2.9-7.1 \text { ) }\end{array}$ & $8(4.2,10.3)^{\mathrm{d}}$ & $5.4(4.8,6.6)$ & 0.03 \\
\hline $\begin{array}{l}\text { Uric acid, mg/dl } \\
\text { (normal range, } 0.15-0.42 \mathrm{mg} / \mathrm{dl} \text { ) }\end{array}$ & $0.36(0.27,0.47)$ & $0.29(0.25,0.36)$ & 0.17 \\
\hline Mean urinary albumin-creatinine ratio & $221.5(10.6,441.9)^{\mathrm{d}}$ & $12.6(6.0,24.9)$ & 0.012 \\
\hline Glomerular filtration rate, $\mathrm{ml} / \mathrm{min} / 1.73 \mathrm{~m}^{2}$ & $48.13 \pm 7.91^{\mathrm{c}}$ & $85.83 \pm 15.4$ & $<0.001$ \\
\hline \multicolumn{4}{|l|}{ Diabetic complications, $\%$} \\
\hline Microalbuminuria & 16.7 & 19.4 & 0.26 \\
\hline Macroalbuminuria & $27.8^{c}$ & 1.0 & $<0.001$ \\
\hline Coronary heart disease & 2.1 & 1.6 & 0.58 \\
\hline Stroke & 7.1 & 13.1 & 0.1 \\
\hline Diabetic peripheral neuropathy & $57.9^{\mathrm{c}}$ & 24.3 & 0.003 \\
\hline Peripheral vascular disease & $10.5^{\mathrm{d}}$ & 1.0 & 0.01 \\
\hline \multicolumn{4}{|l|}{ SUDOSCAN results, $\mu \mathrm{S}$} \\
\hline Hands ESC value & $56.74 \pm 20.5$ & $59.34 \pm 18.65$ & 0.06 \\
\hline Feet ESC value & $49.11 \pm 23.13$ & $59.58 \pm 21.84$ & 0.66 \\
\hline Diabetic nephropathy value & $44.69 \pm 11.9^{c}$ & $63.16 \pm 16.5$ & $<0.001$ \\
\hline \multicolumn{4}{|l|}{ Medication use, $\%$} \\
\hline Metformin & 10.5 & 24.8 & 0.172 \\
\hline Insulin & 42.1 & 41.9 & 0.98 \\
\hline Statins & 8.3 & 39.4 & 0.83 \\
\hline $\begin{array}{l}\text { Angiotensin converting enzyme inhibitor } \\
\text { or angiotensin II receptor blocker, } \%\end{array}$ & 68.4 & 44.8 & 0.06 \\
\hline
\end{tabular}

Data are presented as the mean \pm standard deviation, median (interquartile range) values or number of patients $(\%)$. ${ }^{\mathrm{a}} \mathrm{CKD}$ was defined as $\mathrm{GFR}$ of $<60 \mathrm{ml} / \mathrm{min} / 1.73 \mathrm{~m}{ }^{2}$. ${ }^{b}$ Non-CKD was defined as GFR of $\geq 60 \mathrm{ml} / \mathrm{min} / 1.73 \mathrm{~m}^{2}$. ${ }^{\mathrm{C}} \mathrm{P}<0.01$ vs. patients without $\mathrm{CKD}$ and ${ }^{\mathrm{d}} \mathrm{P}<0.05$. CKD, chronic kidney disease; T2DM, type 2 diabetes mellitus; BP, blood pressure; ESC, electrochemical skin conductance. 
Table II. Spearman correlation analysis between glomerular filtration rate and clinical characteristics.

\begin{tabular}{lcc}
\hline Variable & $\mathrm{R}$ & P-value \\
\hline Age & $-0.48^{\mathrm{a}}$ & $<0.001$ \\
Duration of diabetes & $-0.22^{\mathrm{b}}$ & 0.015 \\
Body mass index & -0.11 & 0.24 \\
Waist-hip ratio & $-0.25^{\mathrm{a}}$ & 0.006 \\
Systolic BP & -0.18 & 0.052 \\
Diastolic BP & 0.013 & 0.89 \\
Glycated hemoglobin & 0.15 & 0.11 \\
Glycated albumin & 0.07 & 0.47 \\
Fasting blood glucose & 0.15 & 0.16 \\
Total cholesterol & 0.15 & 0.1 \\
Triglycerides & 0.08 & 0.37 \\
High-density lipoprotein cholesterol & 0.01 & 0.9 \\
Low-density lipoprotein cholesterol & $0.2^{\mathrm{b}}$ & 0.03 \\
Serum creatinine & $-0.47^{\mathrm{a}}$ & $<0.001$ \\
Blood urea nitrogen & $-0.31^{\mathrm{a}}$ & 0.001 \\
Uric acid & $-0.31^{\mathrm{a}}$ & 0.001 \\
Mean urinary albumin-creatinine ratio & -0.16 & 0.08 \\
Hands ESC value & 0.13 & 0.14 \\
Feet ESC value & $0.23^{\mathrm{b}}$ & 0.01 \\
SUDOSCAN-DN value & $0.52^{\mathrm{a}}$ & $<0.001$ \\
\hline
\end{tabular}

${ }^{\mathrm{a}} \mathrm{P}<0.01$ and ${ }^{\mathrm{b}} \mathrm{P}<0.05$. BP, blood pressure; ESC, electrochemical skin conductance; DN, diabetic nephropathy.

and lower GFR level compared patients with score $\geq 59.5$ (all $\mathrm{P}<0.001)$. A significantly increased rate of stroke (13.2 vs. $3.1 \%$; $\mathrm{P}<0.01$ ), diabetic peripheral neuropathy (41.9 vs. $15.4 \%$; $\mathrm{P}<0.001)$ and peripheral vascular disease ( 4.9 vs. $1.0 \% ; \mathrm{P}<0.05)$ was observed in the group of T2DM patients with DN level $<59.5$. A significant decrease in the ESC level of hands and feet $(\mathrm{P}<0.001)$ in the group of $\mathrm{T} 2 \mathrm{DM}$ patients with $\mathrm{DN}$ level $<59.5$ was also detected in the study, as presented in Table IV. ESC values of hands in DN the $\geq 59.5$ group was $65.1 \pm 17.1$ vs. $56.7 \pm 20.5$ in the $\mathrm{DN}<59.5$ group and $\mathrm{ESC}$ of feet in $\mathrm{DN} \geq 59.5$ group was $66.4 \pm 19.5$ vs. $51.2 \pm 21.7$ in the $\mathrm{DN}<59.5$ group. Both of these differences are significant $(\mathrm{P}<0.001)$.

\section{Discussion}

Sudomotor function is a subtype of autonomic function reflecting the integrity of sympathetic $\mathrm{C}$ fibers innervating the sweat glands, which can be highly susceptible to damage by metabolic processes, including longstanding diabetes (9,28-31). Processes downstream to sustained hyperglycemia, including activation of protein kinase $\mathrm{C}$, activation of the polyol pathway and formation of advanced glycosylation end products, which are known to drive diabetic renal changes, have been implicated in causing reduction of endoneurial blood flow as well as causing direct nerve injury $(1,3,32)$. Therefore, a previous study proposed that sudomotor dysfunction may have similar pathogenic mechanisms to diabetic kidney disease and SUDOSCAN may be used to perform early detection of CKD in diabetic
TableIII.Multiple linear regression analysis between glomerular filtration rate and clinical characteristics in Chinese patients with type 2 diabetes.

\begin{tabular}{lcc}
\hline Clinical factors & Standard $\beta$-coefficient & P-value \\
\hline Age & $-0.368^{\mathrm{a}}$ & $<0.001$ \\
Duration of diabetes & $-0.227^{\mathrm{a}}$ & 0.008 \\
Glycated hemoglobin & 0.11 & 0.21 \\
Body mass index & -0.48 & 0.24 \\
Waist-hip ratio & $-0.24^{\mathrm{b}}$ & 0.007 \\
Low-density lipoprotein & 0.016 & 0.85 \\
cholesterol & & \\
SUDOSCAN-DN score & $0.42^{\mathrm{a}}$ & $<0.001$
\end{tabular}

${ }^{\mathrm{a}} \mathrm{P}<0.01 ;{ }^{\mathrm{b}} \mathrm{P}=0.008$. DN, diabetic nephropathy.

patients (33). This proposal has been supported by previous studies that used SUDOSCAN to detect CKD in diabetic patients based on the premise that patients with CKD are likely to have vascular and nerve dysfunction (9). In a previous study, SUDOSCAN, as the modified and improved generation of EZSCAN with different built in algorithms, was reported to be effective in detecting CKD in a large cross-sectional sample of Chinese patients with T2DM (5). Statistics in that study showed the area under ROC curve of SUDOSCAN-DN score for CKD was 0.75 (95\% CI, 0.72-0.79), which indicated SUDOSCAN may be useful in detecting patients at risk of having CKD. In 2011, Gin et al (30) first reported EZSCAN as the new screening tool for kidney disease in Chinese patients with T2DM. Freedman et al (11) studied 390 African and European American patients with T2DM and 166 controls, and found an independent association between ESC and GFR in African Americans.

In the present cross-sectional study, GFR was used instead of eGFR as the diagnostic standard for patients with or without CKD. The diagnostic value of SUDOSCAN in the detection of CKD in T2DM patients was evaluated using ROC curve analysis. The area under ROC curve was 0.85 (95\% CI, 0.76-0.93) with a cut-off point of 59.5 for DN score. This cut-off point had $57.6 \%$ sensitivity and $100 \%$ specificity in detecting CKD. Compared with those without CKD, patients with CKD were older, had longer duration of disease, lower blood hemoglobin and more diabetic complications including peripheral neuropathy and peripheral vascular disease. By multiple linear regression analysis, the associated risk factors with GFR were found to be SUDOSCAN-DN score, disease duration, age, waist-hip ratio and hemoglobin level. Clinical characteristics were also compared in two groups divided by cut-off point of DN drawn from ROC analysis, and a lower GFR level was observed in patients with DN score $<59.5$.

The natural progression of kidney dysfunction in T2DM involves the gradual progress from albuminuria to declined GFR. Microalbuminuria is traditionally viewed as an early indicator of diabetic renal involvement, but its predictive value for renal dysfunction is challenged by poor sensitivity and specificity as well as many impact factors including pathological or physiological processes unrelated to diabetes such as 
Table IV. Clinical characteristics of patients with or without CKD by SUDOSCAN-DN score.

\begin{tabular}{|c|c|c|c|}
\hline Variable & DN score $<59.5^{\mathrm{a}}(\mathrm{n}=79)$ & DN score $\geq 59.5^{\mathrm{b}}(\mathrm{n}=97)$ & P-value \\
\hline Sex, n (M/F) & $45 / 34$ & $48 / 49$ & 0.052 \\
\hline Age, years & $64.7 \pm 9.9^{c}$ & $46.7 \pm 9.9$ & $<0.001$ \\
\hline Duration of T2DM, years & $10(5,15)^{\mathrm{c}}$ & $6.5(1,9.5)$ & $<0.001$ \\
\hline Smoking, $\%$ & 20.9 & 36.7 & 0.13 \\
\hline Family history of T2DM, \% & 39.5 & 49.4 & 0.20 \\
\hline \multicolumn{4}{|l|}{ Body mass index, $\mathrm{kg} / \mathrm{m}^{2}$} \\
\hline Male & $24(21,26)$ & $25(23,28)$ & 0.09 \\
\hline Female & $25(22,26)$ & $22(20,26.3)$ & 0.24 \\
\hline \multicolumn{4}{|l|}{ Waist-hip ratio } \\
\hline Male & $0.96(0.91,1.02)$ & $0.96(0.91,0.99)$ & 0.55 \\
\hline Female & $0.92(0.86,0.98)$ & $0.93(0.86,0.98)$ & 0.77 \\
\hline Systolic BP, mmHg & $132.9 \pm 14.2$ & $126.9 \pm 15.2$ & 0.006 \\
\hline Diastolic BP, mmHg & $80.2 \pm 10.2$ & $80.4 \pm 9.4$ & 0.84 \\
\hline Glycated hemoglobin, $\%$ & $8.2 \pm 2$ & $8.8 \pm 2.1$ & 0.06 \\
\hline Low-density lipoprotein cholesterol, mmol/l & $2.21(1.81,2.66)$ & $2.47(1.88,2.96)$ & 0.48 \\
\hline High-density lipoprotein cholesterol, mmol/l & $1.03(0.9,1.3)$ & $0.95(0.82,1.2)$ & 0.07 \\
\hline Triglyceride, $\mathrm{mmol} / \mathrm{l}$ & $1.2(0.9,1.9)^{\mathrm{c}}$ & $1.8(1.2,2.6)$ & 0.003 \\
\hline Cholesterol, mmol/l & $4.4(3.5,5.2)$ & $4.4(3.7,4.8)$ & 0.39 \\
\hline Serum creatinine, $\mu \mathrm{mol} / 1$ & $66.9 \pm 27.6$ & $60.0 \pm 13.8$ & 0.36 \\
\hline Blood urea nitrogen, mmol/l & $5.5(4.6,7.3)$ & $5.2(4.5,6.2)$ & 0.054 \\
\hline Uric acid, mg/dl & $0.29(0.25,0.40)$ & $0.31(0.26,0.38)$ & 0.70 \\
\hline Mean urinary albumin-creatinine ratio & $290(10.6,441.9)$ & $16(6.0,24.9)$ & 0.16 \\
\hline Glomerular filtration rate, $\mathrm{ml} / \mathrm{min} / 1.73 \mathrm{~m}^{2}$ & $72.5 \pm 19.7^{\mathrm{c}}$ & $89.9 \pm 16$ & $<0.001$ \\
\hline \multicolumn{4}{|l|}{ Diabetic complications, $\%$} \\
\hline Microalbuminuria & 14.1 & 20.5 & 0.12 \\
\hline Macroalbuminuria & 0.9 & 1.4 & 0.08 \\
\hline Coronary heart disease & 2.3 & 1.5 & 0.32 \\
\hline Stroke & $13.2^{\mathrm{c}}$ & 3.1 & 0.005 \\
\hline Diabetic peripheral neuropathy & $41.9^{c}$ & 15.4 & $<0.001$ \\
\hline Peripheral vascular disease & $4.9^{\mathrm{d}}$ & 1.0 & 0.048 \\
\hline \multicolumn{4}{|l|}{ SUDOSCAN results, $\mu \mathrm{S}$} \\
\hline Hands ESC value & $56.7 \pm 20.5^{\mathrm{c}}$ & $65.1 \pm 17.1$ & $<0.001$ \\
\hline Feet ESC value & $51.2 \pm 21.7^{\mathrm{c}}$ & $66.4 \pm 19.5$ & $<0.001$ \\
\hline $\mathrm{DN}$ value & $46.8 \pm 10.6^{c}$ & $73.8 \pm 11.6$ & $<0.001$ \\
\hline \multicolumn{4}{|l|}{ Medication use, $\%$} \\
\hline Metformin & 23.3 & 27.8 & 0.5 \\
\hline Insulin & 38.4 & 50.6 & 0.11 \\
\hline Statins & 24.1 & 24.1 & 0.57 \\
\hline $\begin{array}{l}\text { Angiotensin converting enzyme inhibitor or } \\
\text { angiotensin II receptor blocker, } \%\end{array}$ & $52.1^{\mathrm{c}}$ & 47.9 & 0.003 \\
\hline
\end{tabular}

Data are presented as the mean \pm standard deviation, median (interquartile range) values or number of patients $(\%)$. ${ }^{\mathrm{a}} \mathrm{CKD}$ was defined as $\mathrm{DN}$ score of $<59.5$ according to ROC analysis. ${ }^{b}$ Non-CKD was defined as GFR $\geq 59.5 \mu \mathrm{S}$. ${ }^{\mathrm{d}} \mathrm{P}<0.01$ and ${ }^{\mathrm{d}} \mathrm{P}<0.05$ vs. DN score $\geq 59.5$. CKD, chronic kidney disease; T2DM, type 2 diabetes mellitus; BP, blood pressure; ESC, electrochemical skin conductance; DN, diabetic nephropathy.

posture, exercise, obesity and infection (2). This may explain the insignificant correlation between UCAR and DN score that was observed in the current study.

The current study had some limitations. The sample size of this cross-sectional cohort was not large enough to analyze the correlation between kidney function with all associated clinical characteristics. The possibility of selection bias could not be excluded in drawing the conclusion of high specificity of SUDOSCAN-DN score in detecting CKD. Further studies with larger sample sizes are needed to confirm the clinical use of SUDOSCAN for diagnosing risk of CKD.

The majority of guidelines recommend regular screening for complications and risk factors in patients with diabetes, including eye, foot, blood and urine examinations $(1,3,28,34,35)$. 
The results of the current study suggest that SUDOSCAN may be considered as a useful screening tool in an outpatient service or low resource setting, as part of a CKD screening program, due to its low invasiveness and convenience.

In conclusion, the current results suggested that the assessment of sudomotor function using SUDOSCAN may provide an effective screening method for the detection of kidney dysfunction in Chinese patients with T2DM.

\section{Acknowledgements}

This study was supported by grants from the National Natural Science Foundation of China (grant no. 81370884, to Professor Bin Lu), the Shanghai New Excellent Youth Program (grant no. XYQ2013120, to Professor Bin Lu), Pudong Municipal Commission of Health and Family Planning (PW2014D-2, to Professor Bin Lu; and PW2013D-2, to Professor HongLi Shi) and the Shanghai Science and Technology Committee Program (grant no. 14411962200, to Professor Yiming Li).

\section{References}

1. Hass VM: Updated management of chronic kidney disease in patients with diabetes. JAAPA 27: 17-22, 2014.

2. MacIsaac RJ, Ekinci EI and Jerums G: 'Progressive diabetic nephropathy. How useful is microalbuminuria?: Contra'. Kidney Int 86: 50-57, 2014.

3. Tuttle KR, Bakris GL, Bilous RW, Chiang JL, de Boer IH, Goldstein-Fuchs J, Hirsch IB, Kalantar-Zadeh K, Narva AS, Navaneethan SD, et al: Diabetic kidney disease: A report from an ADA Consensus Conference. Am J Kidney Dis 64: 510-533, 2014.

4. Schold JD, Navaneethan SD, Jolly SE, Poggio ED, Arrigain S, Saupe W, Jain A, Sharp JW, Simon JF, Schreiber MJ Jr and Nally JV Jr: Implications of the CKD-EPI GFR estimation equation in clinical practice. Clin J Am Soc Nephrol 6: 497-504, 2011.

5. Levey AS, Stevens LA, Schmid CH, Zhang YL, Castro AF III, Feldman HI, Kusek JW, Eggers P, Van Lente F, Greene T, et al: A new equation to estimate glomerular filtration rate. Ann Intern Med 150: 604-612, 2009.

6. Korhonen PE, Kivelä SL, Aarnio PT, Kautiainen H, Järvenpää S and Kantola IM: Estimating glomerular filtration rate in hypertensive subjects: Comparison of the chronic kidney disease epidemiology collaboration (CKD-EPI) and modification of diet in renal disease (MDRD) study equations. Ann Med 44: 487-493, 2012.

7. Teo BW, Koh YY, Toh QC, Li J, Sinha AK, Shuter B, Sethi S and Lee EJ: Performance of the CKD-EPI creatinine-cystatin C glomerular filtration rate estimation equations in a multiethnic Asian population. Singapore Med J 55: 656-659, 2014.

8. Eranki VG, Santosh R, Rajitha K, Pillai A, Sowmya P, Dupin J and Calvet JH: Sudomotor function assessment as a screening tool for microvascular complications in type 2 diabetes. Diabetes Res Clin Pract 101: e11-e13, 2013.

9. Ramachandran A, Moses A, Shetty S, Thirupurasundari CJ, Seeli AC, Snehalatha C, Singvi S and Deslypere JP: A new non-invasive technology to screen for dysglycaemia including diabetes. Diabetes Res Clin Pract 88: 302-306, 2010.

10. Casellini CM, Parson HK, Richardson MS, Nevoret ML and Vinik AI: Sudoscan, a noninvasive tool for detecting diabetic small fiber neuropathy and autonomic dysfunction. Diabetes Technol Ther 15: 948-953, 2013.

11. Freedman BI, Bowden DW, Smith SC, Xu J and Divers J: Relationships between electrochemical skin conductance and kidney disease in Type 2 diabetes. J Diabetes Complications 28: 56-60, 2014

12. Luk AO, Fu WC, Li X, Ozaki R, Chung HH, Wong RY, So WY, Chow FC and Chan JC: The clinical utility of SUDOSCAN in chronic kidney disease in Chinese patients with type 2 diabetes. PLoS One 10: e0134981, 2015.

13. van den Brand JA, van Boekel GA, Willems HL, Kiemeney LA, den Heijer $M$ and Wetzels JF: Introduction of the CKD-EPI equation to estimate glomerular filtration rate in a Caucasian population. Nephrol Dialysis Transplantat 26: 3176-3181, 2011.
14. Yuan X, Zhang J, Tang K, Quan C, Tian Y, Li H, Ao G and Qiu L: Determination of glomerular filtration rate with CT measurement of renal clearance of iodinated contrast material versus 99mTc-DTPA dynamic imaging 'Gates' Method: A Validation Study in Asymmetrical Renal Disease. Radiology 282: 552-560, 2017.

15. Ma YC, Zuo L, Zhang CL, Wang M, Wang RF and Wang HY: Comparison of 99mTc-DTPA renal dynamic imaging with modified MDRD equation for glomerular filtration rate estimation in Chinese patients in different stages of chronic kidney disease. Nephrol Dial Transplant 22: 417-423, 2007.

16. Qiao X, Zhang S, Zhao W, Ye H, Yang Y, Zhang Z, Miao Q, Hu R, Li Y and Lu B: Serum phosphorylated neurofilament-heavy chain, a potential biomarker, is associated with peripheral neuropathy in patients with type 2 diabetes. Medicine (Baltimore) 94: e1908, 2015.

17. Fox CS, Golden SH, Anderson C, Bray GA, Burke LE, de Boer IH, Deedwania P, Eckel RH, Ershow AG, Fradkin J, et al: Update on prevention of cardiovascular disease in adults with type 2 diabetes mellitus in light of recent evidence: A scientific statement from the American Heart Association and the American Diabetes Association. Circulation 132: 691-718, 2015.

18. Joint Committee for Developing Chinese guidelines on Prevention and Treatment of Dyslipidemia in Adults: Chinese guidelines on prevention and treatment of dyslipidemia in adults. Zhonghua Xin Xue Guan Bing Za Zhi 35: 390-419, 2007 (In Chinese).

19. Sudchada P and Laehn S: Comparisons of GFR estimation using the CKD Epidemiology Collaboration (CKD-EPI) equation and other creatinine-based equations in Asian population: A systematic review. Int Urol Nephrol 48: 1511-1517, 2016.

20. Liu X, Gan X, Chen J, Lv L, Li M and Lou T: A new modified CKD-EPI equation for Chinese patients with type 2 diabetes. PLoS One 9: e109743, 2014.

21. Xiong Q, Lu B, Ye H, Wu X, Zhang T and Li Y: The diagnostic value of neuropathy symptom and change score, neuropathy impairment score and michigan neuropathy screening instrument for diabetic peripheral neuropathy. Eur Neurol 74: 323-327, 2015.

22. Herráiz-Adillo Á, Martínez-Vizcaíno V, Cavero-Redondo I, Álvarez-Bueno C, Garrido-Miguel M and Notario-Pacheco B: Diagnostic accuracy study of an oscillometric ankle-brachial index in peripheral arterial disease: The influence of oscillometric errors and calcified legs. PLoS One 11: e0167408, 2016.

23. Aboyans V, Criqui MH, Abraham P, Allison MA, Creager MA, Diehm C, Fowkes FG, Hiatt WR, Jönsson B, Lacroix P, et al: Measurement and interpretation of the ankle-brachial index: A scientific statement from the American Heart Association. Circulation 126: 2890-2909, 2012.

24. Eknoyan G, Hostetter T, Bakris GL, Hebert L, Levey AS, Parving HH, Steffes MW and Toto R: Proteinuria and other markers of chronic kidney disease: A position statement of the national kidney foundation (NKF) and the national institute of diabetes and digestive and kidney diseases (NIDDK). Am J Kidney Dis 42: 617-622, 2003.

25. Yajnik CS, Kantikar VV, Pande AJ and Deslypere JP: Quick and simple evaluation of sudomotor function for screening of diabetic neuropathy. ISRN Endocrinol 2012: 103714, 2012.

26. Lee CC, Perkins BA, Kayaniyil S, Harris SB, Retnakaran R, Gerstein HC, Zinman B and Hanley AJ: Peripheral neuropathy and nerve dysfunction in individuals at high risk for type 2 diabetes: The PROMISE cohort. Diabetes Care 38: 793-800, 2015.

27. Chen SC, Hsiao PJ, Huang JC, Lin KD, Hsu WH, Lee YL, Lee MY, Chang JM and Shin SJ: Abnormally low or high ankle-brachial index is associated with proliferative diabetic retinopathy in type 2 diabetic mellitus patients. PLoS One 10: e0134718, 2015.

28. Vinik AI, Nevoret ML and Casellini C: The new age of sudomotor function testing: A sensitive and specific biomarker for diagnosis, estimation of severity, monitoring progression and regression in response to intervention. Front Endocrinol (Lausanne) 6: 94, 2015.

29. Calvet JH, Dupin J, Winiecki H and Schwarz PE: Assessment of small fiber neuropathy through a quick, simple and non invasive method in a German diabetes outpatient clinic. Exp Clin Endocrinol Diabetes 121: 80-83, 2013. 
30. Gin H, Baudoin R, Raffaitin CH, Rigalleau V and Gonzalez C: Non-invasive and quantitative assessment of sudomotor function for peripheral diabetic neuropathy evaluation. Diabetes Metab 37: 527-532, 2011.

31. Chen L, Chen X, Ding R, Shi Q Jr and Hu D: Evaluation of EZSCAN as a screening tool for impaired glucose metabolism. Diabetes Res Clin Pract 100: 210-214, 2013.

32. Garasto S, Fusco S, Corica F, Rosignuolo M, Marino A, Montesanto A, De Rango F, Maggio M, Mari V, Corsonello A and Lattanzio F: Estimating glomerular filtration rate in older people. Biomed Res Int 2014: 916542, 2014.

33. Ozaki R, Cheung KK, Wu E, Kong A, Yang X, Lau E, Brunswick P, Calvet JH, Deslypere JP and Chan JC: A new tool to detect kidney disease in Chinese type 2 diabetes patients: Comparison of EZSCAN with standard screening methods. Diabetes Technol Ther 13: 937-943, 2011.
34. Chamberlain JJ, Rhinehart AS, Shaefer CF Jr and Neuman A: Diagnosis and management of diabetes: Synopsis of the 2016 American diabetes association standards of medical care in diabetes. Ann Intern Med 164: 542-552, 2016.

35. Tesfaye S, Boulton AJ, Dyck PJ, Freeman R, Horowitz M, Kempler P, Lauria G, Malik RA, Spallone V, Vinik A, et al: Diabetic neuropathies: Update on definitions, diagnostic criteria, estimation of severity, and treatments. Diabetes Care 33: 2285-2293, 2010. 